\title{
Updated Australian guidelines for mild asthma: what's changed and why?
}

\section{Helen K Reddel \\ Professor, Woolcock \\ Institute of Medical \\ Research, University of \\ Sydney}

\section{Keywords}

asthma, budesonideformoterol, corticosteroids

Aust Prescr 2020;43:220-4 https://doi.org/10.18773/ austprescr.2020.076

\section{SUMMARY}

The Australian asthma guidelines have recently been updated and include additional treatment options for adults and adolescents with mild asthma.

Mild asthma is not necessarily a benign condition and patients are still at risk of severe flare-ups, particularly if they overuse short-acting beta ${ }_{2}$ agonists such as a salbutamol inhaler.

For adults and adolescents with mild asthma, the updated guidelines include as-needed inhaled low-dose budesonide-formoterol as an alternative to daily low-dose inhaled corticosteroid plus as-needed short-acting beta ${ }_{2}$ agonist.

The budesonide-formoterol combination should be taken as needed to provide symptom relief and reduce the risk of severe exacerbations.

\section{Introduction}

A recent update to Australian asthma guidelines was launched in September 2020 (version 2.1).' It provides evidence-based, practical online guidance for health professionals, particularly in primary care. The 2020 updates focus on expanded options for the treatment of mild asthma in adults and adolescents. Key changes have been made around the rationale and evidence for management options, and the factors to consider in shared decision making.

Many adults and adolescents with asthma (50-70\%) have mild disease, that is an estimated 1.1-1.6 million Australians. Asthma is classified as mild if it can be well controlled with a short-acting beta ${ }_{2}$ agonist (SABA) such as salbutamol, or a low-dose inhaled corticosteroid (ICS). From the perspective of patients and clinicians, asthma is usually regarded as mild if symptoms are infrequent or quickly relieved by a salbutamol inhaler, with little interference on their day-to-day life. These patients may not even seek medical advice since in Australia salbutamol inhalers can be purchased overthe-counter. In a large Australian population survey, $39 \%$ of asthma patients (aged $\geq 16$ years) had not used a preventer inhaler in the previous year. Almost half of these usually bought relievers over-the-counter. ${ }^{2}$

\section{Mild asthma is not necessarily benign}

In the past, it was thought that mild asthma was of little concern, and that treating it with as-needed SABAs for symptom relief and an occasional course of oral corticosteroids was a simple and inexpensive therapeutic strategy. However, patients with mild asthma are still at risk of severe exacerbations, particularly if they overuse SABAs. Overuse is generally defined as dispensing of three or more canisters of salbutamol in a year (an average of 1.6 or more puffs per day). This is associated with a doubling of the risk of emergency department presentation ${ }^{3}$ and an increased risk of asthma death. ${ }^{4}$ Approximately $15 \%$ of asthma deaths occur in patients with apparently mild asthma. ${ }^{5}$

The risk of a severe flare-up can be reduced by half (or more) with daily low-dose ICS, for example fluticasone propionate $\leq 200 \mathrm{microgram} /$ day or budesonide $\leq 400$ microgram/day. There is no evidence of adverse effects at these doses. However, patients are rarely adherent with this therapy, and poor adherence is associated with an increased risk of severe flare-ups requiring oral corticosteroids. ${ }^{6}$

In the past, an occasional course of oral corticosteroids was considered acceptable, but as few as four or five lifetime courses of oral corticosteroids are associated with an increased risk of adverse effects such as osteoporosis, pneumonia, cataracts and diabetes. ${ }^{7}$ To mitigate these risks, clinicians from the Global Initiative for Asthma (GINA) initiated clinical trials that have culminated in evidence-based changes to global, and now Australian, treatment options for mild asthma. ${ }^{8}$

\section{Low-dose budesonide-formoterol}

Australian asthma guidelines now include as-needed inhaled low-dose budesonide-formoterol (eformoterol) for patients with mild asthma.

Budesonide is an ICS and formoterol is a quick-onset long-acting beta ${ }_{2}$ agonist ( $L A B A$ ). This combination gives rapid symptom relief and also reduces the risk of severe exacerbations. It provides an alternative to regular daily low-dose ICS plus an as-needed SABA (see Level 2 of treatment in Fig.) 


\section{What does 'as-needed' mean?}

Patients should use the low-dose budesonideformoterol inhaler in the same way as a salbutamol inhaler. This means they should use it as needed to relieve asthma symptoms, or when they are going to encounter a known trigger (e.g. allergen, exercise). If their asthma symptoms increase, they should take more doses to relieve the symptoms. It is extremely important to explain the meaning of 'as-needed' with this new approach as it is different from the way patients typically use a preventer inhaler.

\section{Which inhalers can be used and how often?}

For mild asthma, as-needed budesonide-formoterol can only be prescribed with the following inhalers:

- Dry powder inhaler (Symbicort Turbuhaler 200/6 or DuoResp Spiromax 200/6 containing budesonide-formoterol 200/6 micrograms). The patient should take one inhalation when needed for symptom relief, or before exposure to known triggers. If symptoms persist after a few minutes, they can take an additional inhalation. No more than six inhalations should be used on any single occasion, and no more than 12 in a day.

- Pressurised metered dose inhaler (Symbicort Rapihaler 100/3 containing budesonideformoterol 100/3 micrograms). The patient should take two separate puffs when needed, as described above, with no more than 12 puffs on a single occasion, and no more than 24 in a day.

The choice of inhaler will depend on patient preference and confirmation that they are able to use the inhaler correctly. However, of the two dry powder inhalers, Symbicort Turbuhaler 200/6 is approved for adults and adolescents aged 12 years and over, whereas the DuoResp Spiromax 200/6 is only approved for adults 18 years and over. The Symbicort Rapihaler $100 / 3$ is approved for adults and adolescents.

Before prescribing one of these inhalers, always check that the patient can use the inhaler correctly. Videos on how to use inhalers are available.

Patients should be advised that they do not need to rinse and spit out after taking as-needed doses of budesonide-formoterol. This recommendation is supported by safety data from studies in more than 30,000 patients, with no increase in risk of candidiasis or hoarse voice. However, patients prescribed maintenance ICS only or ICS-SABA are still advised to rinse and spit out after their maintenance doses.

Budesonide-formoterol 400/12 dry powder inhaler and 200/6 pressurised metered dose inhaler should not be used as reliever inhalers because the dose of formoterol would escalate too quickly when extra doses were taken.
Other ICS-LABA combinations also cannot be used for symptom relief, either because the onset of action of the LABA is too slow (e.g. fluticasone propionatesalmeterol), or the inhaler is approved only for oncedaily use (e.g. fluticasone furoate-vilanterol).

\section{How does as-needed budesonide- formoterol work?}

First, although formoterol is a LABA, it has a rapid onset of action, and the combination of an ICS and formoterol reduces symptoms and bronchoconstriction as quickly and as effectively as a SABA alone, so it can be used for symptom relief. This has been recommended for more than 10 years as the reliever in 'maintenance and reliever therapy' (MART) at Levels 3-4 of asthma treatment (see Fig.). ${ }^{9}$

Second, a rapid increase in doses of both budesonide and formoterol as soon as symptoms increase, even on a single day, reduces the risk of progression to a severe flare-up over the following days or weeks compared to using a salbutamol inhaler alone..$^{10,11}$

Third, not all exacerbations are inflammatory, so using an inhaler providing both an ICS and more stable bronchodilatation treats both types of flare-ups.

\section{How strong is the evidence for the new recommendations?}

The new recommendations are supported by highquality evidence from five clinical trials totalling approximately 10,000 patients. Participants had mild asthma and were eligible for Level 2 treatment, either by taking a SABA alone, or with well- or partly controlled asthma on Level 2 treatment (low-dose ICS, or montelukast). Patients with very poorly controlled asthma were not included as they should receive Level 3 treatment (see Fig.). Two 12-month studies in participants aged $\geq 12$ years were doubleblind regulatory studies in patients previously taking either SABA alone or ICS or montelukast.12,13 A further two 12-month studies in adults were more pragmatic open-label studies with patients using the as-needed inhaler as they would in real life..$^{14,15}$ In one of these studies all patients were previously using SABA alone $^{14}$ and in the other, $70 \%$ were previously using low-medium-dose ICS. ${ }^{15}$

The main focus of the studies was on the risk of severe flare-ups, since symptoms are not burdensome for most patients with mild asthma. Importantly, as-needed low-dose budesonide-formoterol reduced the risk of severe flare-ups requiring oral corticosteroids or emergency care by $64-65 \%$ compared with SABAs alone..$^{12,14}$ This effect was the same,,$^{12,13}$ or better, ${ }^{14,15}$ than regular ICS plus an 


\section{Fig. Selecting and adjusting asthma medication for adults and adolescents}

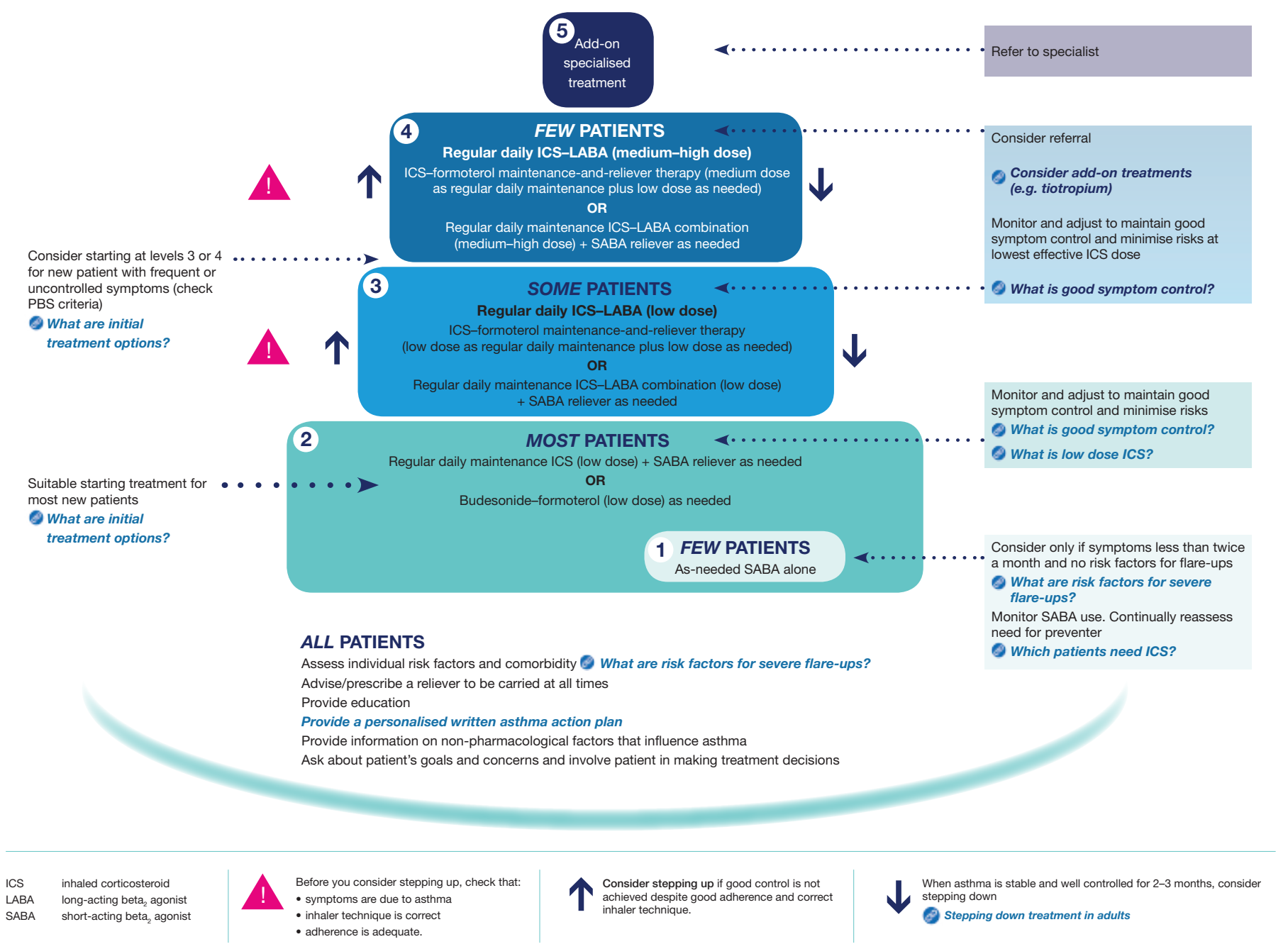

Reproduced, with permission, from Australian Asthma Handbook, version 2.1.' @ National Asthma Council Australia 2020. Accessed 2020 Oct 27.

as-needed SABA. A recent meta-analysis of all four studies found that as-needed budesonide-formoterol reduced the risk of emergency department visits for asthma by $35 \%$ compared with regular ICS plus as-needed SABA. ${ }^{16}$

Symptom control, lung function and asthma-related quality of life were slightly better with daily ICS than with budesonide-formoterol in three studies. However, these differences were not large enough to be felt by the patients and did not become cumulatively worse over 12 months. ${ }^{12-14}$ With budesonide-formoterol use averaging 3-4 times a week, airway inflammation (measured by exhaled nitric oxide) was significantly reduced and did not worsen over 12 months. ${ }^{14,15}$ These benefits were achieved with a very low budesonide dose (median approximately 60-100 microgram/day).
Another study in patients with mild asthma found that as-needed budesonide-formoterol taken for symptom relief, and before exercise, reduced exercise-induced bronchoconstriction to the same extent as daily ICS with an as-needed SABA. ${ }^{17}$ This means that patients prescribed as-needed budesonide-formoterol do not need to be prescribed a SABA for pre-exercise use.

\section{Established options for mild asthma treatment remain}

Regular ICS plus an as-needed SABA is still a very effective and safe treatment for mild asthma. It reduces severe flare-ups by more than half, even in patients with infrequent symptoms. However, before prescribing this, explain the importance of taking the ICS every day as patients who do not are at greater risk of severe flare-ups. 


\section{Which treatment for which patient?}

Adults and adolescents with a diagnosis of asthma who are currently using a salbutamol inhaler alone are suitable for as-needed low-dose budesonideformoterol or a regular ICS plus as-needed SABA (Level 2 treatment). This is unless their asthma is very poorly controlled (e.g. they need their reliever inhaler more than twice a day) or they have low lung function.

As-needed low-dose budesonide-formoterol is also suitable for patients whose asthma is well controlled with regular low-dose ICS. This is much safer than stepping down to a SABA alone.

In mild asthma, unlike in severe asthma, patients do not need to be 'phenotyped'. As-needed budesonideformoterol reduces severe exacerbations compared with regular ICS or SABA alone, and with similar symptom control. This is regardless of whether the patient does or does not have 'type 2' inflammation (blood eosinophils or exhaled nitric oxide). ${ }^{14,15}$

Treatment with a salbutamol inhaler alone should only be considered if patients have symptoms less than twice a month and have no risk factors for exacerbations (e.g. smoking) or have not had an exacerbation in the previous year. There have been no studies of any asthma treatment in patients with symptoms less than twice a month.

Cost to the patient is often important. For as-needed budesonide-formoterol, with the usage seen in clinical trials (median 3-4 doses/week), the average monthly cost to the patient can be as little as one-sixth of that for a daily low-dose preventer, depending on the specific ICS. ${ }^{18}$

\section{Other updates in the 2020 Australian asthma guidelines}

More asthma medicines have been added to the 2020 guidelines including:

- once-daily fluticasone furoate 50 microgram for children aged $\geq 5$ years and for adults and adolescents whose ICS dose can be tapered

- beclomethasone-formoterol 100/6 microgram inhaler for maintenance therapy in moderatesevere asthma. This medicine is not yet listed on the Pharmaceutical Benefits Schedule

- dupilumab (anti-interleukin-4-receptor) injectable add-on therapy for severe type 2 asthma. This adds to the three existing monoclonal antibodies (benralizumab, mepolizumab and omalizumab) approved for severe asthma in Australia. Their use requires specialist referral. Dupilumab is not yet listed on the Pharmaceutical Benefits Schedule.

\section{Conclusion and recommendations}

When considering the new asthma guidelines, it is important to remember the basics of asthma management:

- Confirm the diagnosis of asthma.

- Involve patients in shared decision-making and self-management education.

- Prescribe an ICS-containing treatment for almost all patients with asthma to control symptoms and reduce the risk of severe flare-ups. Consider treatment with SABA alone only if patients have asthma symptoms less than twice a month and no history of a flare-up in the past year.

- For patients with mild asthma, a new treatment option is as-needed low-dose budesonideformoterol. This is much safer than SABA-only treatment and is as effective as maintenance ICS without the need to take daily treatment.

- Avoid over-reliance and overuse of salbutamol inhalers.

- Review and adjust treatment periodically - do not 'set and forget'.

- Check and correct inhaler technique and adherence at every opportunity.

- Provide a written asthma action plan for every patient. The National Asthma Council action plan library includes simple fillable Australian-designed action plans for patients prescribed budesonideformoterol maintenance and reliever therapy or reliever-only therapy (including Turbuhaler action plan and Rapihaler action plan). It also provides conventional action plans. $<$

Helen Reddel or her institute have received honoraria for providing independent advice in advisory boards/ steering committees for - AstraZeneca, Boehringer Ingelheim, Chiesi, GlaxoSmithKline and Novartis; for an international data safety monitoring board for AstraZeneca, GlaxoSmithKline, Merck, and Novartis; consulting for AstraZeneca and GlaxoSmithKline; and for providing independent medical education at symposia funded by AstraZeneca, Boehringer Ingelheim, GlaxoSmithKline, Mundipharma, Novartis and Teva. Helen Reddel's institute has received unrestricted research grants from AstraZeneca, GlaxoSmithKline and Novartis.

Helen Reddel was one of four members of the Global Initiative for Asthma (GINA) who, from 2007 onwards, made multiple applications to industry and to government agencies for randomised controlled trials of as-needed inhaled corticosteroids-formoterol to reduce the risk of severe exacerbations in mild asthma. When 
AstraZeneca eventually agreed to conduct two such studies, she was a member of the steering committee for these studies. Helen Reddel was also a member of the steering committee for two additional randomised controlled trials of this regimen, sponsored by the Health Research Council of New Zealand.

Helen Reddel is Chair of the GINA Science Committee, and a member of the National Asthma Council
Guidelines Committee. As all members of the GINA Science Committee and several members of the Australian Asthma Handbook Guidelines Committee are active asthma researchers, the corresponding Boards of Directors conducted a detailed review of processes for handling of potential conflicts of interest, before the above studies were reviewed by the relevant committees.

\section{REFERENCES}

1. National Asthma Council Australia. Australian Asthma Handbook. Version 2.1. Melbourne: National Asthma Counci Australia; 2020. http://www.asthmahandbook.org.au [cited 2020 Oct 27]

2. Reddel HK, Ampon RD, Sawyer SM, Peters MJ. Risks associated with managing asthma without a preventer: urgent healthcare, poor asthma control and over-thecounter reliever use in a cross-sectional population survey. BMJ Open 2017;7:e016688. https://doi.org/10.1136/ bmjopen-2017-016688

3. Stanford RH, Shah MB, D'Souza AO, Dhamane AD, Schatz M. Short-acting $\beta$-agonist use and its ability to predict future asthma-related outcomes. Ann Allergy Asthma Immunol 2012;109:403-7. https://doi.org/10.1016/j.anai.2012.08.014

4. Nwaru BI, Ekström M, Hasvold P, Wiklund F, Telg G, Janson $C$. Overuse of short-acting $\beta_{2}$-agonists in asthma is associated with increased risk of exacerbation and mortality: a nationwide cohort study of the global SABINA programme. Eur Respir J 2020;55:1901872. https://doi.org/ 10.1183/13993003.01872-2019

5. Dusser D, Montani D, Chanez P, de Blic J, Delacourt C Deschildre A, et al. Mild asthma: an expert review on epidemiology, clinical characteristics and treatment recommendations. Allergy 2007;62:591-604. https://doi.org/ 10.1111/j.1398-9995.2007.01394.x

6. Engelkes M, Janssens HM, de Jongste JC, Sturkenboom MC Verhamme KM. Medication adherence and the risk of severe asthma exacerbations: a systematic review. Eur Respir J 2015;45:396-407. https://doi.org/10.1183/09031936.00075614

7. Price DB, Trudo F, Voorham J, Xu X, Kerkhof M, Ling Zhi Jie J, et al. Adverse outcomes from initiation of systemic corticosteroids for asthma: long-term observational study. J Asthma Allergy 2018;11:193-204. https://doi.org/ 10.2147/JAA.S176026

8. Reddel HK, FitzGerald JM, Bateman ED, Bacharier LB, Becker A, Brusselle G, et al. GINA 2019: a fundamental change in asthma management: treatment of asthma with shortacting bronchodilators alone is no longer recommended for adults and adolescents. Eur Respir J 2019;53:1901046. https://doi.org/10.1183/13993003.01046-2019

9. Sobieraj DM, Weeda ER, Nguyen E, Coleman CI, White CM, Lazarus SC, et al. Association of inhaled corticosteroids and long-acting beta-agonists as controller and quick relief therapy with exacerbations and symptom control in persistent asthma: a systematic review and meta-analysis. JAMA 2018;319:1485-96. https://doi.org/10.1001/jama.2018.2769
10. Buhl R, Kuna P, Peters MJ, Andersson TL, Naya IP, Peterson S, et al. The effect of budesonide/formoterol maintenance and reliever therapy on the risk of severe asthma exacerbations following episodes of high reliever use: an exploratory analysis of two randomised, controlled studies with comparisons to standard therapy. Respir Res 2012;13:59. https://doi.org/10.1186/1465-9921-13-59

11. O'Byrne PM, FitzGerald JM, Bateman ED, Barnes PJ, Zheng J, Gustafson P, et al. Effect of a single day of increased as-needed budesonide-formoterol use on short-term risk of severe exacerbations in patients with mild asthma: a posthoc analysis of the SYGMA 1 study. Lancet Respir Med. Epub 2020 Oct 1. https://doi.org/10.1016/s2213-2600(20)30416-1

12. O'Byrne PM, FitzGerald JM, Bateman ED, Barnes PJ, Zhong N, Keen C, et al. Inhaled combined budesonideformoterol as needed in mild asthma. N Engl J Med 2018:378:1865-76. https://doi.org/10.1056/NEJMoa1715274

13. Bateman ED, Reddel HK, O’Byrne PM, Barnes PJ, Zhong N Keen $C$, et al. As-needed budesonide-formoterol versus maintenance budesonide in mild asthma. N Engl J Med 2018;378:1877-87. https://doi.org/10.1056/NEJMoa1715275

14. Beasley R, Holliday M, Reddel HK, Braithwaite I, Ebmeier S, Hancox RJ, et al.; Novel START Study Team. Controlled trial of budesonide-formoterol as needed for mild asthma. N Engl J Med 2019;380:2020-30. https://doi.org/10.1056/ NEJMoa1901963

15. Hardy J, Baggott C, Fingleton J, Reddel HK, Hancox RJ, Harwood M, et al.; PRACTICAL study team. Budesonideformoterol reliever therapy versus maintenance budesonide plus terbutaline reliever therapy in adults with mild to moderate asthma (PRACTICAL): a 52-week, open-label, multicentre, superiority, randomised controlled trial. Lancet 2019;394:919-28. https://doi.org/10.1016/ S0140-6736(19)31948-8

16. Hatter L, Bruce P, Braithwaite I, Holliday M, Fingleton J, Weatherall $M$, et al. ICS-formoterol reliever versus ICS and SABA reliever in asthma: a systematic review and metaanalysis. ERJ Open Research 2020; in press. https://doi.org/10.1183/23120541.00701-2020

17. Lazarinis N, Jørgensen L, Ekström T, Bjermer L, Dahlén B, Pullerits T, et al. Combination of budesonide/formoterol on demand improves asthma control by reducing exerciseinduced bronchoconstriction. Thorax 2014;69:130-6. https://doi.org/10.1136/thoraxjnl-2013-203557

18. Reddel HK, Lembke K, Zwar NJ. The cost of asthma medicines. Aust Prescr 2018;41:34-6. https://doi.org/ 10.18773/austprescr.2018.011 